\title{
Feedback of Individual Genetic Results to Research Participants: Is It Feasible in Europe?
}

\author{
Isabelle Budin-Ljøsne,,2 Deborah Mascalzoni,,4 Sirpa Soini, ${ }^{3}$ Helena Machado, Jane Kaye, \\ Heidi Beate Bentzen, ${ }^{1,2,8}$ Emmanuelle Rial-Sebbag, ${ }^{9}$ Flavio D'Abramo, ${ }^{10}$ Michał Witt, ${ }^{11}$ \\ Geneviève Schamps, ${ }^{12}$ Višnja Katić, ${ }^{13}$ Dusanca Krajnovic, ${ }^{14}$ Working Group $1,^{15}$ and Jennifer R. Harris ${ }^{16}$
}

Background: There is growing consensus that individual genetic research results that are scientifically robust, analytically valid, and clinically actionable should be offered to research participants. However, the general practice in European research projects is that results are usually not provided to research participants for many reasons. This article reports on the views of European experts and scholars who are members of the European COST Action CHIP ME IS1303 (Citizen's Health through public-private Initiatives: Public health, Market and Ethical perspectives) regarding challenges to the feedback of individual genetic results to research participants in Europe and potential strategies to address these challenges.

Materials and Methods: A consultation of the COST Action members was conducted through an email survey and a workshop. The results from the consultation were analyzed following a conventional content analysis approach. Results: Legal frameworks, professional guidelines, and financial, organizational, and human resources to support the feedback of results are largely missing in Europe. Necessary steps to facilitate the feedback process include clarifying legal requirements to the feedback of results, developing harmonized European best practices, promoting interdisciplinary and cross-institutional collaboration, designing educational programs and cost-efficient IT-based platforms, involving research ethics committees, and documenting the health benefits and risks of the feedback process.

Conclusions: Coordinated efforts at pan-European level are needed to enable equitable, scientifically sound, and socially robust feedback of results to research participants.

\section{Introduction}

$\mathrm{T}$ HE QUESTION OF whether to provide feedback on individual genetic research results from genome sequencing to research participants has been discussed for almost two decades. ${ }^{1}$ Although the debate is still intense, there is growing consensus among bioethicists, researchers, and policy makers that research participants should be provided with at least some genetic results. ${ }^{2}$ Research groups and research funders have recently developed guidelines and recommendations $\mathrm{s}^{3,4}$

\footnotetext{
${ }^{1}$ Centre for Medical Ethics, Institute of Health and Society, University of Oslo, Oslo, Norway.

${ }^{2}$ Norwegian Cancer Genomics Consortium, Kreftgenomikk.no, Oslo, Norway.

${ }^{3}$ Center for Research Ethics and Bioethics, Uppsala University, Uppsala, Sweden.

${ }^{4}$ Center for Biomedicine, EURAC, Bolzano, Italy.

${ }^{5}$ Helsinki Biobank, Helsinki University Hospital, Helsinki, Finland.

${ }^{6}$ Centre for Social Studies, University of Coimbra, Coimbra, Portugal.

${ }^{7}$ Nuffield Department of Population Health, Centre for Health, Law and Emerging Technologies (HeLEX), University of Oxford, Oxford, United Kingdom.

${ }^{8}$ Norwegian Research Center for Computers and Law, Faculty of Law, University of Oslo, Oslo, Norway.

${ }^{9}$ UMR 1027, Inserm, Université de Toulouse, Toulouse, France.

${ }^{10}$ Charité-Universitätsmedizin Berlin, Berlin, Germany.

${ }_{11}^{11}$ Institute of Human Genetics, Polish Academy of Sciences, Poznań, Poland.

${ }^{12}$ Centre for Medical and Biomedical Law, Université Catholique de Louvain, Leuven, Belgium.

${ }^{13}$ School of Medicine, University of Rijeka, Rijeka, Croatia.

${ }^{14}$ Faculty of Pharmacy, Belgrade University, Belgrade, Serbia.

${ }^{15}$ COST Action CHIP ME IS1303 “Citizen's Health through public-private Initiatives: Public health, Market and Ethical perspectives," European Commission, Brussels, Belgium.

${ }^{16}$ Department of Genetics and Bioinformatics, Norwegian Institute of Public Health, Oslo, Norway.
}

(C) Isabelle Budin-Ljøsne et al., 2016; Published by Mary Ann Liebert, Inc. This Open Access article is distributed under the terms of the Creative Commons Attribution Noncommercial License (http://creativecommons.org/licenses/by-nc/4.0/) which permits any noncommercial use, distribution, and reproduction in any medium, provided the original author(s) and the source are credited. 
that encourage researchers to provide participants with genetic research results, including secondary findings, which are analytically valid, clinically significant, and clinically actionable, that is, offer reliable information about health conditions that can be medically prevented or treated. ${ }^{3}$ However, these guidelines are not completely congruent with policies recently developed in Europe for the feedback of genetic results in clinical settings. ${ }^{5,6}$ This lack of harmonization reflects, in part, differences between the genome sequencing analyses conducted for clinical care versus those used in research. Clinical applications are generally limited to the analysis of specific sets of genes to establish a diagnosis or determine the best treatment alternatives. In contrast, research is often discovery oriented and involves conducting analyses encompassing a broader spectrum of variants or genome-wide inquiry. Consequently, there is a greater likelihood that research will generate incidental or other findings that cannot be readily interpreted, but, which still require ethical guidelines regarding how these findings are handled.

With a few recent exceptions, ${ }^{7,8}$ the current practice in most European research projects is that individual genetic research results are not provided to research participants. ${ }^{9}$ Such practice is, however, expected to be challenged as an increasing number of large-scale research projects are planned or have been launched across Europe, which utilize next-generation sequencing technologies, and most likely will produce individual research results of potential health utility for research participants. ${ }^{10,11}$ Another force impacting the practice surrounding return-of-results stems from the research participants themselves, who are increasingly interested in accessing their genetic research results ${ }^{12,13}$ and interacting with researchers. ${ }^{14}$

The development of ethically and socially robust feedback mechanisms for providing genetic research results to research participants relies on the identification of potential challenges that may hinder such feedback in Europe, exploration of intercountry similarities concerning these challenges, and determination of whether these challenges can be addressed in a harmonized way. This is particularly relevant given the types of challenges encountered by several projects located outside of Europe that have started to provide results to their participants. ${ }^{15-21}$ For instance, data from some projects showed that it was difficult to know whether results could be provided to research participants when the original informed consent did not address this possibility. ${ }^{16}$

Another problem relates to the burden associated with allotting the necessary time and resources needed to implement a meaningful feedback process when the services of genetic counselors and clinicians are not available. ${ }^{17,18}$ Moreover, projects often did not have the necessary resources to use the services of laboratories that are accredited to verify the accuracy of the results, and struggled to evaluate the clinical utility of the results in the absence of reference nomenclatures establishing the pathogenicity of variants. ${ }^{19,20}$ Finally, some projects reported that it was difficult to know which specific results could be legally provided to participants ${ }^{21}$ and often found that research ethics committees were reluctant to support the feedback process. ${ }^{20}$

BioSHaRE-EU (Biobank Standardisation and Harmonisation for Research Excellence in the European Union), ${ }^{22}$ a collaborative research project funded by the European Commission Seventh Collaboration Framework (2010-2015), developed frameworks and tools for the harmonization and standardization of biobank activities. ${ }^{23}$ Through its "Ethics" and "Strategic Integration, Coordination, and Dissemination" work packages, it interfaced and worked closely with the COST Action CHIP ME IS1303 (Citizen's Health through public-private Initiatives: Public health, Market and Ethical perspectives), ${ }^{24}$ a European Union framework, which brings together 95 professionals from 25 European countries with expertise in genetics, medicine, bioethics, law, psychology, social sciences and humanities, and informatics. This article reports on results from a consultation with the COST Action members regarding challenges to the feedback of individual genetic results to research participants in Europe and potential ways to address these challenges.

\section{Materials and Methods}

Between July and August 2014, the chairs of WG1 (BudinLjøsne and Mascalzoni) conducted an email survey among the COST Action members consisting of an open-ended questionnaire to inquire about challenges and practical issues that may impede the feedback of clinically actionable genetic results to research participants in their country and to identify potential steps that could be taken to facilitate such feedback. The COST Action members were asked, whenever possible, to coordinate responses within their country. To follow up on the information provided through the email survey, WG1 convened a 1-day workshop at the University of Coimbra, Portugal, in October 2014, which included 43 members of the COST Action from 21 European countries. The workshop was organized as an open space technology (OST) day, ${ }^{25}$ an approach to organizing meetings that enables participants to openly discuss a specific theme without having to follow a predefined detailed agenda. The workshop was moderated by a COST Action member with expertise in leading OST events.

Notes were taken by appointed participants during the workshop and gathered by the WG1 chairs at the end of the day. The data from the email survey and the workshop notes were collated, summarized, and analyzed using a content analysis approach in an inductive way. ${ }^{26}$ Three categories emerged from the data: legal, financial, and organizational/societal issues. Coding was conducted independently by Budin-Ljøsne and Mascalzoni and disagreements in abstractions were discussed with Soini and Machado and resolved by consensus. Interrater reliability and reflection were maximized through comparing coding between all the authors.

\section{Results}

Nineteen questionnaires were collected, providing information from 14 of the 25 COST Action countries (Bosnia and Herzegovina, Croatia, Czech Republic, Estonia, Finland, Germany, Greece, Italy, Norway, Poland, Portugal, Serbia, Slovenia, and United Kingdom). In addition, representatives from eight countries (Belgium, Denmark, France, Iceland, Ireland, Malta, The Netherlands, and Sweden) contributed to the workshop discussions. The COST Action members identified challenges to the feedback of individual research results to research participants in Europe, which fall into three broad categories spanning legal, financial, and organizational/societal issues as described below and summarized in Table 1.

\section{Challenges to the feedback of individual genetic results to research participants}

Legal challenges. The current legal landscape in Europe provides a framework for returning results under the Convention on Human Rights and Biomedicine, ${ }^{27}$ the accompanying 
Table 1. Challenges to the Feedback of Individual Genetic Results to Research Participants in Europe and Potential Strategies to Address Challenges
Challenges
Legal challenges
Unclear how current provisions in European conventions should be interpreted
European conventions often neither ratified by countries nor implemented in national legislation
When national legislation exists, unclear how it applies in practice
Financial challenges
No specific funding to support the feedback process
Unclear whether healthcare systems are willing to finance the feedback process
Organizational/societal challenges
Lack of professional guidelines and best practices to govern the feedback of results
Lack of qualified staff (e.g., genetic counselors) to feedback results to research participants
Insufficient collaboration between professions to support the feedback process
Lack of awareness among research participants regarding the possibility of feedback
Potential strategies to address challenges
Develop harmonized European guidelines for the feedback of results
Allocate specific funding to the feedback process
Document the health benefits of providing genetic results to research participants
Involve research ethics committees early in the design of the feedback process
Promote interdisciplinary and cross-institutional collaboration, for example, through expert networks
Develop educational programs for healthcare professionals
Explore cost-efficient and IT-based tools (e.g., dynamic consent, web-based feedback)
Discuss the modalities of the feedback process with research participants and the general public

Additional Protocol on Biomedical Research, ${ }^{28}$ and through the Council of Ministers Recommendation on biological materials of human origin. ${ }^{29}$ These legal instruments state that research participants have a right to know any information collected on their health. The Additional protocol also outlines a researcher's "duty of care," stating that, "If research gives rise to information of relevance to the current or future health or quality of life of research participants, this information must be offered to them. That shall be done within a framework of healthcare or counseling. In communication of such information, due care must be taken to protect confidentiality and to respect any wish of a participant not to receive such information." ${ }^{28}$ However, there is still uncertainty about which kind of information equals relevant health information and what a researcher's duty of care entails. Furthermore, while many European countries have ratified the Convention and implemented it into national legal frameworks, there are still notable exceptions such as the United Kingdom, Belgium, Sweden, and Germany, and the number of countries that have ratified the Additional Protocol on Biomedical Research remains small.

Only a few countries such as Estonia, ${ }^{30}$ France, ${ }^{31}$ Finland, ${ }^{32}$ Italy, ${ }^{33}$ and Norway ${ }^{34}$ are known to have national regulations offering research participants the possibility to access (usually upon request) their genetic and other results. However, the modalities of such access remain largely unclear. For instance, it is uncertain whether access to raw sequences should be granted to research participants. Furthermore, national legislations often require that research data and clinical patient data are processed separately, thus potentially hindering the use of research data for clinical purposes.

Financial challenges. Currently, there is no specific financing dedicated to support the feedback process. However, such a process may require additional funding, for instance to verify the analytical validity of the findings, cover the cost of genetic counseling, or to pay for the necessary administrative support to recontact participants. Funding schemes for research normally do not encompass the cost of feedback. Si- milarly, it is unclear whether healthcare systems are willing to finance the feedback of genetic results that are not produced in a clinical setting and do not comply with clinical standards.

Organizational/societal challenges. Lack of professional guidelines and best practices. Professional guidelines and best practices for the feedback of results to research participants are largely missing in Europe, with the exception of a few countries such as the United Kingdom and Norway. ${ }^{7,35-37}$ Where guidelines do exist, they are often general and do not offer guidance regarding the specific genetic variants for which feedback of results should be provided to participants. In the absence of clear guidelines, the research participants' access to their genetic results may be handled on a case-bycase basis. This may lead to inequitable treatment, for instance if some projects provide results to their participants, while other similar projects do not provide results or decide to apply different criteria for doing so. This may be a particularly salient issue in multicenter European studies where individuals participating in the same study, but living in different countries, may have differential access to their results.

Lack of qualified staff. Providing genetic results to research participants within a qualified professional framework may be difficult as there are few genetic counselors and clinical geneticists in Europe, in particular in rural regions. Furthermore, the qualifications of genetic counselors often vary due to the lack of standard training requirements. General practitioners and family doctors, who could potentially contribute in the feedback process, may not have the necessary education in genetics or the capacity to perform additional tasks, in particular in countries where there are too few medical doctors per inhabitant. Prioritization of national healthcare provisions also plays a major role here; the workload of professionals is primarily allocated based on clinical needs.

Insufficient interdisciplinary and cross-institutional collaboration. The feedback process normally requires that professions work together. For instance, researchers and 
healthcare professionals may collaborate to validate research results to a clinical standard or to include results communication in a healthcare setting procedure. However, such collaboration is often not well established. While clinicians leading research projects may be able to use their established networks to organize such activities, researchers operating outside of clinical settings, for instance in biobanks projects, may struggle to develop the necessary alliances.

Lack of awareness regarding the possibility of receiving research results. In most established research projects, the participants are not aware that genetic results may be provided to them, as this possibility was not mentioned in the original informed consent. Collecting the renewed consent of participants to allow for the feedback process may be burdensome, expensive, or even impossible for research projects with limited resources. However, future informed consents are expected to inform participants about the possibility of feedback, thus potentially eliminating the need for renewed consent.

\section{Proposed strategies to address challenges}

The strategies proposed by the COST Action members to address the challenges described above are listed below and summarized in Table 1.
Clarify legal requirements for the feedback of results. The current legal situation is ambiguous for both researchers and participants. However, any pursuit of legally binding access rights to research results ought to also pay attention to practical and economical obstacles. Researchers should be encouraged to have clear policies regarding whether or not they report back the results, and in the former case, what would be the process for validation of results, counseling, and care. Further international legal harmonization in this area should be sought.

Elaborate harmonized European best practices. European researchers, research funders, research and healthcare institutions, medical societies, and community representatives should collaborate at a European level to develop harmonized European best practices for the feedback of genetic research results to research participants. These discussions should take into consideration the specific needs, contexts, laws, and cultural norms of European research. Recent recommendations for the management of genetic results in research settings (listed in Table 2$)^{7,35-47}$ and clinical settings ${ }^{5,6}$ may be used to guide such work.

Allocate specific funding to the feedback process. Funding schemes should include specific funding that can be granted to researchers and healthcare services that establish collaboration to provide results to participants. The expected cost

Table 2. Main Recommendations and Guidelines for the Feedback of Genetic Research Results to Research Participants

Origin
Canada (LDP)
Canada ( $\left.\mathrm{P}^{3} \mathrm{G}\right)$
Canada (RMGA)
Norway (NBAB)
The Netherlands
United Kingdom
(MRC and Wellcome Trust)
United Kingdom (UK10K)
United Kingdom (PHG
Foundation)
USA

USA (CSER and eMERGE)

USA (NHLBI)

USA (Presidential Commission for the Study of Bioethical Issues)

Recommendations/guidelines

An implementation framework for the feedback of individual research results and incidental findings in research ${ }^{38}$

Return of research results and incidental findings policy statement ${ }^{41}$

Statement of principles on the return of research results and incidental findings ${ }^{40}$

Proposal for a guideline for the use of genome sequencing and genome data in clinical and research settings 35

Feedback of individual genetic results to research participants: in favor of a qualified disclosure policy ${ }^{43}$

Framework on the feedback of health-related findings in research ${ }^{37}$

Managing clinically significant findings in research: the UK10K example ${ }^{7}$

Managing incidental and pertinent findings from WGS in the 100,000 Genomes Project ${ }^{36}$

Managing incidental findings and research results in genomic research involving biobanks and archived data sets ${ }^{42}$

Return of genomic results to research participants: the floor, the ceiling, and the choices in between ${ }^{39}$

Ethical and practical guidelines for reporting genetic research results to study participants: updated guidelines from a National Heart, Lung, and Blood Institute ${ }^{44}$

Anticipate and communicate: Ethical management of incidental and secondary findings in the clinical, research, and Direct-to-Consumer contexts ${ }^{47}$

\begin{tabular}{lc} 
Origin & Recommendations/guidelines for pediatric research \\
\hline Canada $\left(\mathrm{P}^{3} \mathrm{G}\right)$ & $\begin{array}{c}\text { Return of whole-genome sequencing results in pediatric research: a statement of the } \mathrm{P} 3 \mathrm{G} \\
\text { international pediatrics platform }\end{array}$ \\
Canada $(\mathrm{ICOB})$ & $\begin{array}{r}\text { Guidelines for return of research results from pediatric genomic studies: deliberations of } \\
\text { the Boston Children's Hospital Gene Partnership Informed Cohort Oversight Board }\end{array}$ \\
\hline
\end{tabular}

CSER, Clinical Sequencing Exploratory Research; eMERGE, Electronic Medical Records and Genomics Network; ICOB, Informed Cohort Oversight Board; LDP, Liver Disease Project; MRC, Medical Research Council; NBAB, Norwegian Biotechnology Advisory Board; NHLBI, National Heart, Lung, and Blood Institute; PHG Foundation, Foundation for Genomics and Population Health; P ${ }^{3}$ G, Public Population Project in Genomics and Society; RMGA, Network of Applied Genetic Medicine. 
of the feedback process should be determined as early as possible in research projects and specified in research applications. $^{2}$

Document the health benefits of genetic research results. Providing genetic research results to research participants may enable clinicians to establish more precise diagnoses and prevent serious conditions. It may also help research participants inform their own health decisions. Documenting the health benefits of genetic research results may convince funders, policy makers, and decision makers to take the necessary legal, financial, and organizational steps to support the feedback process.

Involve research ethics committees in the feedback process. Research ethics committees should carefully consider the feedback process before research is commenced and evaluate to what extent and how results may be provided to research participants. These committees may also develop an ethical framework for determining the researchers' responsibilities for feedback of results and reviewing the appropriateness of researchers' plans for communicating results.

Enhance the feedback process through interdisciplinary and cross-institutional collaboration. Expert networks of clinicians, molecular biologists, bioinformaticians, and geneticists should be established in research projects to facilitate the feedback process. If necessary, alliances may be developed with commercial actors for the supply of specific services (e.g., laboratory services), which are not available to research teams, but are needed to provide results.

Increase counseling expertise. Educational programs should be developed to enhance genetic knowledge among healthcare professionals such as medical doctors, clinicians, clinical ethicists, psychologists, nutritionists, nurses, biologists, and laboratory geneticists who are strategically placed in the community and may potentially contribute to the feedback process. Such programs could for instance build upon the common set of core competences in genetics recently proposed by the European Society of Human Genetics. ${ }^{48}$

Explore cost-efficient solutions and tools. Participants' preferences regarding the use of interactive and cost-efficient ITbased tools such as dynamic consent ${ }^{49}$ and web-based ${ }^{50}$ and telephone-based platforms ${ }^{51}$ for access to genetic results should be explored. Cognitive computing for the translation of genetic results into information of clinical utility ${ }^{52}$ may also be considered. This includes research to investigate ethical and legal requirements pertaining to the use of such platforms.

Increase research participants' and the general public's awareness regarding the feedback of results. Promoting citizens' participation in science is central to the European scientific reform. ${ }^{53}$ Researchers should develop mechanisms to discuss with citizens and research participants the modalities of the feedback of results, for instance through public consultations, debates, and social networks. While it may often not be feasible to provide individual level results, the overall results of the study could be meaningful for people and provided as an acknowledgement that their participation and contribution are important.

\section{Discussion}

The perspective of European researchers and scholars who are members of the COST Action CHIP ME is that providing genetic research results to research participants in Europe is, at present, hardly feasible due to numerous legal, financial, organizational, and societal challenges. Our study results corroborate observations made by respondents to a recent European public consultation who emphasized that providing genetic results to research participants may be difficult in the absence of agreement on best practices, clarity regarding which results to provide, standards for validation of research results, and allocated funding. ${ }^{54}$ Similar observations have been made in clinical genetics settings where the feedback process is often reported to be practically unfeasible due to legal, psychological, and organizational issues. ${ }^{55}$ Logistical issues may also be encountered when results are available, but the research participants who should receive the results cannot be found, such as when personal identifiers are removed to protect the participants' privacy, which is a common practice in biobank research. ${ }^{38}$

To help overcome these challenges, the COST Action members believe that the proposed recommendations would help develop a unified strategy to support a pan-European approach to the feedback of results. These recommendations are founded on important intercountry commonalities that emerged in our research. First, challenges to the feedback process are strikingly similar across European countries; addressing these challenges collaboratively may therefore reduce duplication of efforts and reinforce cross-border research collaboration. Second, European countries are committed to provide, to the extent of their available resources and capacities, equitable access to healthcare of appropriate quality. ${ }^{27}$ If, as most COST Action members believe, research participants' access to genetic research results that are clinically significant and actionable can contribute to better prevention and healthcare, such access should be made equal and fair across research projects and across countries. However, this is only possible if legal provisions, best practices, and organizational structures for the feedback of results are harmonized throughout Europe. Third, European research is increasingly collaborative, cross-national, and multicentered. Researchers rely steadily more on European financial instruments such as the Horizon 2020 of the EU Research and Innovation programme ${ }^{56}$ for funding. In a context of strained resources and limited time, it therefore makes sense to give priority to developing European harmonized strategies for the feedback of results that can be applicable in all research projects independent of their geographical location, rather than national strategies that may differ dramatically between countries or even require contradictory action. It should, however, be noted that developing European harmonized strategies for the feedback of genetic research results to research participants does not mean that a single approach to the feedback process must be adopted throughout Europe. The specificities and varying contexts of research projects and countries should be taken into consideration and strategies for the feedback of results adapted accordingly.

The recommendations proposed by the COST members aim to address a wide range of considerations spanning legal, financial, organizational, and societal issues. Realization of the ideas comprising these recommendations will require a stepwise process with some endeavors more readily implementable than others. For instance, involving research committees in the design of the feedback process and developing interdisciplinary and cross-institutional collaboration to support such feedback does not pose critical barriers; established channels already exist for engaging the relevant actors and entities. In contrast, increasing counseling expertise among healthcare professionals, 
documenting the health benefits of genetic research results, and allocating additional funding to the feedback process require more extensive efforts, are time-consuming, and may be difficult to achieve in countries where the financial resources of healthcare systems are scarce. To help move this agenda forward, it is important to work together as a community to build consensus and momentum through projects and initiatives that bring relevant stakeholders together such as this COST action.

Furthermore, we can start to prioritize efforts on those recommendations that can be implemented rapidly and at a reasonable cost. As an illustration, work has already been completed in exploring how the feedback process may be supported through the use of online tools. ${ }^{57}$ Some of these tools are open source and are readily available to research groups. ${ }^{57}$ By incorporating information in the informed consent process about the possibility that genetic results may be provided in the future and offering research participants the opportunity to reflect upon such possibility, research groups may be able to gradually start providing the results that are most urgent. Researchers could take a number of actions such as discussing with their research ethics committee and cooperating with clinical laboratories and clinicians in their network to identify the results that should be given priority. Importantly, researchers urgently need clarification regarding legal requirements for the feedback of results and access to practical guidelines outlining which type of results should be fed back and how. As noted above, such guidelines may be developed on the basis of already existing policies.

A critical consideration going forward is how to best harmonize such policies between clinical and research milieus. The current situation in which clinical recommendations ${ }^{5,6}$ may only be partly transferable to research settings due to differences in methodologies and quality requirements may change rapidly as the methodologies and sequencing coverage used in each setting become more similar. Currently, clinicians often use high levels of sequencing coverage and focus on specific sets of genes to produce precise results that can be used for diagnostic purposes. In contrast, researchers usually produce, in a single test, data for up to billions of individual analytes. ${ }^{58}$ Assessing the analytical performance of genetic tests, including their specificity, sensitivity, and level of precision, is challenging when such large amounts of data are produced. ${ }^{58}$ Similarly, determining which genetic variants have clinical utility is difficult as the significance of most variants detected by researchers is currently unknown, and our current knowledge of polygenic risk assessment is in nascent stages, as is our understanding of population differences associated with the risk of specific variants. Research guidelines will need to include additional criteria and assessment methods to certify the quality and accuracy of genetic results produced through research and provide references to wellannotated genetic reference databases establishing the pathogenicity of variants.

With the rapid changes in technologies and the increased integration of personal genomes and sequencing in healthcare, the divide between research and clinical care may diminish considerably (or completely disappear) with regard to the technical differences underlying genomic information that is generated about a participant versus a patient. This will add new nuance regarding the differences in the requirements between clinical care and research to provide results to the individual.
Providing individual research results to participants is expected to benefit research participants as it enables more proactive behavior, whereby individuals may be able to seek qualified medical help and receive appropriate advice or treatment. However, it is important to consider the risks, as well as the benefits, of providing results. Research participants may react differently when learning about their genetic status: some with anxiety and others with eagerness to act, for instance by starting treatment or undergoing surgery. Knowledge about genetic disease or predisposition may also impact the life of biological relatives and could have significance for future family planning. ${ }^{19}$ It is therefore important that results are provided in a qualified and transparent manner, and in accordance with the participants' wishes, and that researchers specify the extent to which the results are accurate and reliable to guide people's choices and avoid unnecessary harm and distress.

\section{Implications for European decision makers}

Providing individual genetic research results that are clinically useful and actionable is increasingly seen as an ethical and legal obligation, and a healthcare necessity. ${ }^{3}$ Informing research participants about their results makes sense in today's world where patients and research participants are increasingly willing to share their personal health information, ${ }^{59}$ including clinical and lifestyle data, with researchers and healthcare providers and also take initiatives to share their data through web-based portals ${ }^{60}$ and devices. ${ }^{61}$ However, relying solely on the good will and initiative of researchers to provide results to research participants is not sufficient. European policy makers, funders, and research and healthcare institutions have a joint responsibility to ensure that the necessary prerequisites are in place to enable research participants to access their genetic research results of health relevance in an equitable, scientifically sound, and ethically and socially robust way across Europe. The COST Action members will continue their efforts to coordinate activities at the European level to help advance this agenda. We hope that our research results will contribute to increased awareness regarding the need to develop mechanisms that enable biobanks and research groups to fulfill their ethical obligations toward research participants.

\section{Acknowledgments}

The authors would like to thank Professor Heather Skirton, Plymouth University, for skillfully leading the OST workshop in Coimbra; the COST Action CHIP ME chairs of WG2 and WG3 for helping at collecting questionnaires; the COST Action CHIP ME members for their useful contributions; Professor Michael Hummel, Charité-Universitätsmedizin Berlin, Professor Jan Helge Solbakk, University of Oslo, and Professor Jean-Marc Hausman, Université catholique de Louvain, for their comments. This article is based upon work from COST Action IS1303 “Citizen's Health through publicprivate Initiatives: Public health, Market and Ethical perspectives," and is supported by COST (European Cooperation in Science and Technology) (www.cost.eu); the Biobank Standardisation and Harmonisation for Research Excellence in the European Union (BioSHaRE-EU) program, which received funding from the European Union Seventh Framework Programme (FP7/2007-2013) under Grant Agreement No. 
261433; the National Research and Innovation Platform for Personalized Cancer Medicine funded by the Norwegian Research Council (NFR BIOTEK2021/ES495029); the European Union Seventh Framework Programme (FP7/20072013) under Grant Agreement No. 305444 (RD-Connect); the Innovative Medicines Initiative project BTCure (Grant Agreement No. 115142-1); the BioBanking and Molecular Resource Infrastructure of Sweden project financed by the Swedish Research Council (BBMRI)LPC (313010); LegRegPCM (Legal Regulation of Information Processing relating to Personalized Cancer Medicine) funded by the Norwegian Research Council (NFR BIOTEK2021/238999/ O30); the European Research Council, under Grant Agreement No. 648608; and Biobank Norway, funded by the Norwegian Research Council (NFR 197443/F50). JK is funded under Wellcome Trust Award 096599/2/11/Z and the EU F7 project BIOSHARE.

\section{Author Disclosure Statement}

No conflicting financial interests exist.

\section{References}

1. Bredenoord AL, Kroes HY, Cuppen E, et al. Disclosure of individual genetic data to research participants: The debate reconsidered. Trends Genet 2011;27:41-47.

2. Wolf SM. Return of individual research results and incidental findings: Facing the challenges of translational science. Annu Rev Genomics Hum Genet 2013;14:557-577.

3. Knoppers BM, Zawati MH, Senecal K. Return of genetic testing results in the era of whole-genome sequencing. Nat Rev Genet 2015;16:553-559.

4. Shkedi-Rafid S, Dheensa S, Crawford G, et al. Defining and managing incidental findings in genetic and genomic practice. J Med Genet 2014;51:715-723.

5. van El CG, Cornel MC, Borry P, et al. Whole-genome sequencing in health care. Recommendations of the European Society of Human Genetics. Eur J Hum Genet 2013; 21(Suppl 1):S1-S5.

6. Claustres M, Kozich V, Dequeker E, et al. Recommendations for reporting results of diagnostic genetic testing (biochemical, cytogenetic and molecular genetic). Eur J Hum Genet 2014;22:160-170.

7. Kaye J, Hurles M, Griffin H, et al. Managing clinically significant findings in research: The UK10K example. Eur J Hum Genet 2014; 22:1100-1104.

8. Haukkala A, Kujala E, Alha P, et al. The return of unexpected research results in a biobank study and referral to health care for heritable long QT syndrome. Public Health Genomics 2013;16:241-250.

9. Chakradhar S. Many returns: Call-ins and breakfasts hand back results to study volunteers. Nat Med 2015;21:304-306.

10. Genomics England. The 100,000 Genomes Project. Available at: www.genomicsengland.co.uk/the-100000-genomesproject/ Accessed August 31, 2015.

11. Estonian Genome Center, University of Tartu. Available at: www.geenivaramu.ee/en Accessed August 31, 2015.

12. Facio FM, Eidem $H$, Fisher $\mathrm{T}$, et al. Intentions to receive individual results from whole-genome sequencing among participants in the ClinSeq study. Eur J Hum Genet 2013; 21:261-265.

13. Middleton A, Morley KI, Bragin E, et al. Attitudes of nearly 7000 health professionals, genomic researchers and publics toward the return of incidental results from sequencing research. Eur J Hum Genet 2016;24:21-29.

14. Kaye J, Curren L, Anderson N, et al. From patients to partners: Participant-centric initiatives in biomedical research. Nat Rev Genet 2012;13:371-376.

15. Kullo IJ, Haddad R, Prows CA, et al. Return of results in the genomic medicine projects of the eMERGE network. Front Genet 2014;5:50.

16. Fullerton SM, Wolf WA, Brothers KB, et al. Return of individual research results from genome-wide association studies: Experience of the Electronic Medical Records and Genomics (eMERGE) Network. Genet Med 2012;14:424431.

17. Johns AL, Miller DK, Simpson SH, et al. Returning individual research results for genome sequences of pancreatic cancer. Genome Med 2014;6:42.

18. Christensen KD, Roberts JS, Shalowitz DI, et al. Disclosing individual CDKN2A research results to melanoma survivors: Interest, impact, and demands on researchers. Cancer Epidemiol Biomarkers Prev 2011;20:522-529.

19. Lawrence L, Sincan M, Markello T, et al. The implications of familial incidental findings from exome sequencing: The NIH Undiagnosed Diseases Program experience. Genet Med 2014;16:741-750.

20. Keogh LA, Fisher D, Sheinfeld Gorin S, et al. How do researchers manage genetic results in practice? The experience of the multinational Colon Cancer Family Registry. J Community Genet 2014;5:99-108.

21. Klitzman R, Buquez B, Appelbaum PS, et al. Processes and factors involved in decisions regarding return of incidental genomic findings in research. Genet Med 2014;16:311-317.

22. BioSHaRE-EU (Biobank Standardisation and Harmonisation for Research Excellence in the European Union). Available at: www.bioshare.eu Accessed December 18, 2015.

23. BioSHaRE-EU. Catalogue of tools and services for data sharing. Available at: www.bioshare.eu/sites/default/files/ BioSHaRE\%20Catalogue\%20of\%20tools\%20and\%20services \%20for\%20data\%20sharing.pdf Accessed December 18, 2015.

24. COST. COST Action CHIP ME IS1303. Citizen's Health through public-private Initiatives: Public health, Market and Ethical perspectives. Available at: www.cost.eu/COST Actions/isch/Actions/IS1303 Accessed August 31, 2015.

25. Open Space Technology. Available at: http://en.wikipedia. org/wiki/Open_Space_Technology Accessed March 31, 2015.

26. Elo S, Kyngas H. The qualitative content analysis process. J Adv Nurs 2008;62:107-115.

27. Council of Europe. Convention for the protection of Human Rights and Dignity of the Human Being with regard to the Application of Biology and Medicine: Convention on Human Rights and Biomedicine. Available at: http://conventions.coe. int/Treaty/en/Treaties/Html/164.htm Accessed March 31, 2015.

28. Council of Europe. Additional Protocol to the Convention on Human Rights and Biomedicine, concerning Biomedical Research. Available at: http://conventions.coe.int/Treaty/ en/Treaties/Html/195.htm Accessed March 31, 2015.

29. Council of Europe. Recommendation $\operatorname{Rec}(2006) 4$ of the Committee of Ministers to member states on research on biological materials of human origin. Available at: https:// wcd.coe.int/ViewDoc.jsp?id=977859 Accessed March 31, 2015.

30. Riigi Teataja. Estonian Human Genes Research Act. Available at: www.riigiteataja.ee/en/eli/531102013003/consolide Accessed March 31, 2015. 
31. LOI $n^{\circ}$ 2012-300 du 5 mars 2012 relative aux recherches impliquant la personne humaine. Available at: www .legifrance.gouv.fr/affichTexte.do?cidTexte=JORFTEXT000 $025441587 \&$ dateTexte $=\&$ categorieLien $=$ id Accessed March $31,2015$.

32. Ministry of Social Affairs and Health, Finland. Finnish Biobank Act 688/2012. Available at: www.finlex.fi/en/laki/ kaannokset/2012/en20120688.pdf Accessed March 31, 2015.

33. The Garante per la protezione dei dati personali. General Authorisation No. 8/2012 for the Processing of Genetic Data-13 December 2012. Available at: www.garanteprivacy .it/web/guest/home/docweb/-/docweb-display/docweb/2474250 Accessed March 31, 2015.

34. LOV 2008-06-20 nr 44. Lov om medisinsk og helsefaglig forskning (helseforskningsloven). Available at: www. lovdata.no/all/hl-20080620-044.html\#28 Accessed March 31, 2015.

35. Norwegian Biotechnology Advisory Board. Forslag til veileder og retningslinjer for bruk av genomsekvensering og genomdata i klinikk og forskning. Available at: www .bioteknologiradet.no/filarkiv/2012/11/Veileder_genomsek vensering_091112_til_nett.pdf Accessed March 31, 2015.

36. Phg Foundation. Managing incidental and pertinent findings from WGS in the 100,000 Genomes Project. Available at: www.phgfoundation.org/file/13772/ Accessed August 31, 2015.

37. Medical Research Council and Wellcome Trust. Framework on the feedback of health-related findings in research. Available at: www.wellcome.ac.uk/stellent/groups/corporate site/@policy_communications/documents/web_document/ wtp056059.pdf Accessed August 31, 2015.

38. Thorogood A, Joly Y, Knoppers BM, et al. An implementation framework for the feedback of individual research results and incidental findings in research. BMC Med Ethics 2014; $15: 88$.

39. Jarvik GP, Amendola LM, Berg JS, et al. Return of genomic results to research participants: The floor, the ceiling, and the choices in between. Am J Hum Genet 2014;94:818-826.

40. Centre of Genomics and Policy, McGill University. Statement of principles for the return of research results and incidental findings. Available at: www.rmga.qc.ca/en/documents/RMGA Statement_Principles_English_May272013_000.pdf Accessed August 31, 2015.

41. Knoppers BM, Deschenes M, Zawati MH, et al. Population studies: Return of research results and incidental findings Policy Statement. Eur J Hum Genet 2013;21:245-247.

42. Wolf SM, Crock BN, Van NB, et al. Managing incidental findings and research results in genomic research involving biobanks and archived data sets. Genet Med 2012;14:361-384.

43. Bredenoord AL, Onland-Moret NC, Van Delden JJ. Feedback of individual genetic results to research participants: In favor of a qualified disclosure policy. Hum Mutat 2011;32:861-867.

44. Fabsitz RR, McGuire A, Sharp RR, et al. Ethical and practical guidelines for reporting genetic research results to study participants: Updated guidelines from a National Heart, Lung, and Blood Institute working group. Circ Cardiovasc Genet 2010;3:574-580.

45. Knoppers BM, Avard D, Senecal K, et al. Return of wholegenome sequencing results in paediatric research: A statement of the $\mathrm{P} 3 \mathrm{G}$ international paediatrics platform. Eur J Hum Genet 2014;22:3-5.

46. Holm IA, Savage SK, Green RC, et al. Guidelines for return of research results from pediatric genomic studies: Deliberations of the Boston Children's Hospital Gene
Partnership Informed Cohort Oversight Board. Genet Med 2014; 16:547-552.

47. Presidential Commission for the Study of Bioethical Issues. Anticipate and communicate: Ethical management of incidental and secondary findings in the clinical, research, and direct-to-consumer contexts. Available at: http://bioethics.gov/ sites/default/files/FINALAnticipateCommunicate_PCSBI_0. pdf Accessed August 31, 2015.

48. Skirton H, Lewis C, Kent A, et al. Genetic education and the challenge of genomic medicine: Development of core competences to support preparation of health professionals in Europe. Eur J Hum Genet 2010;18:972-977.

49. Williams H, Spencer K, Sanders C, et al. Dynamic consent: A possible solution to improve patient confidence and trust in how electronic patient records are used in medical research. JMIR Med Inform 2015;3:e3.

50. Coriell Personalized Medicine Collaborative. Available at: https://cpmc.coriell.org/ Accessed August 31, 2015.

51. Graves KD, Sinicrope PS, Esplen MJ, et al. Communication of genetic test results to family and health-care providers following disclosure of research results. Genet Med 2014;16:294-301.

52. IBM Watson. Available at: www.ibm.com/smarterplanet/ us/en/ibmwatson/index.html Accessed August 31, 2015.

53. European Commission. Public Consultation "Science 2.0", Science in transition. Available at: http://ec.europa.eu/research/ consultations/science-2.0/background.pdf Accessed August 31, 2015.

54. Council of Europe Committee on Bioethics. Compilation of replies to the public consultation concerning the Working document on research on biological materials of human origin. Available at: www.coe.int/t/dg3/healthbioethic/Activities/ 10_Biobanks/INF(2014)13\%20compilation\%20biobanks\%20e .pdf Accessed August 31, 2015.

55. Otten E, Plantinga M, Birnie E, et al. Is there a duty to recontact in light of new genetic technologies? A systematic review of the literature. Genet Med 2015;17:668-678.

56. European Commission. Horizon 2020. The EU Framework Programme for Research and Innovation. Available at: http:// ec.europa.eu/programmes/horizon2020/en/what-horizon-2020 Accessed August 31, 2015.

57. The Rudy Study. Available at: https://research.ndorms.ox .ac.uk/rudy/ Accessed December 18, 2015.

58. Food and Drug Administration. Developing analytical standards for NGS testing. Available at: www.fda.gov/downloads/ MedicalDevices/NewsEvents/WorkshopsConferences/UCM46 8521.pdf Accessed 17, February 2016.

59. Truven Health Analytics NPR. Health Poll. Data Privacy. Available at: http://truvenhealth.com/Portals/0/NPR-TruvenHealth-Poll/NPRPulseDataPrivacy_Nov2014.pdf Accessed August 31, 2015.

60. Free the data. Available at: www.free-the-data.org/ Accessed August 31, 2015.

61. Apple. ResearchKit. Available at: www.apple.com/research kit/ Accessed August 31, 2015.

\section{Address correspondence to: Isabelle Budin-Ljфsne, MA Centre for Medical Ethics Institute of Health and Society University of Oslo P.O. Box 1130 Blindern Oslo NO-0318 Norway}

E-mail: i.b.ljosne@medisin.uio.no 